Article

\title{
Evaluating State-of-the-Art LEED-NCv4 in the U.S.
}

\author{
Svetlana Pushkar
}

Department of Civil Engineering, Ariel University, Ariel 40700, Israel; svetlanap@ariel.ac.il

Received: 21 December 2019; Accepted: 20 January 2020; Published: 22 January 2020

\begin{abstract}
To date, no empirical evidence has been published on the certification achievements of Leadership in Energy and Environmental Design for New Construction (LEED-NCv4) projects. Therefore, the aim of this study was to determine the trends in LEED-NCv4 Certified, Silver, Gold, and Platinum projects in the U.S. Boxplots were used to measure the consistency of achievement points in categories; Cliff's $\delta$ was used to measure the effect size between possible points and achieved points in categories and credits. The findings show that (1) the categories Sustainable Sites and Energy and Atmosphere were well designed, with consistency increasing from level to level and almost all their credits achieving low-very high points; (2) the categories Water Efficiency and Indoor Environmental Quality showed an average design, and certification levels were found to be inconsistent across the projects and only approximately half of the credits achieved medium or high points, whereas the other half achieved low points; and (3) the categories Location and Transportation and Materials and Resources were the worst designed, with four certification levels found to be inconsistent across the projects and most of the credits achieved low points.
\end{abstract}

Keywords: LEED-NCv4; effect size; credit/category achievement

\section{Introduction}

The concrete industry is currently the largest consumer of natural resources and energy and is a huge producer of solid waste and greenhouse gas emissions. In particular, according to the United Nations Environment Program for Sustainable Buildings and Construction [1], buildings consume 40\% of energy worldwide and produce $40 \%$ of the world's solid waste and $30 \%$ of global greenhouse gas emissions. To decrease the harmful influence of buildings on the environment, the common worldwide approach is implementing building certification under green rating systems.

The Building Research Establishment Environmental Assessment Method (BREEAM) [2], the Assessment System for Built Environment Efficiency (CASBEE) [3], Green Star [4], and Leadership in Energy and Environmental Design (LEED) [5], in addition to others, have been established in the United Kingdom, Japan, Australia, and the United States, respectively. The systems include similar environmental categories, such as energy, water, material, management, health and well-being, and transport, and each of these categories have one or several credits with deterministic performance requirements. When a project team considers credit requirements, projects receive one or several points depending on weight (importance) of this credit. According to the total sum of the awarded points, a project receives an appropriate certification level. The systems, however, face similar concerns regarding categories and credits: (1) category-related environmental issues are emphasized so social and economic issues are almost completely ignored, (2) the suggested deterministic credit-related scoring ignores uncertainty in value judgments about credit performance, and (3) credit-related weighting is not well supported with no consensus on how credit importance should be derived [6].

LEED is the most recognized rating system, applied not only in the United States but also internationally [7]. LEED was established by the U.S. Green Building Council (USGBC), which is a private sector organization. The abovementioned early green rating system-related concerns are 
also relevant to LEED. In applying the triple bottom line, which emprises environmental, social, and economic sustainability, LEED emphasizes the environmental aspect ( $83 \%$ of all the credits are environmentally-related), thereby ignoring economic and social issues, as only $1 \%$ and $16 \%$ of all the credits are economic- and social-related, respectively [8]. When applying weights to the credits, LEED places more importance on active energy design through installation of energy-efficient heating, ventilation, and air conditioning (HVAC) systems ( $82 \%$ of all the possible points in the energy category) and less on passive energy design through use of bio-climatic and passive solar aspects in building design (18\% of all the possible points in the energy category) [9].

New versions LEED and the other rating systems are being constantly developed and improved. In 1998, the USGBC launched LEED v1.0 for new construction buildings (LEED-NC). Additional versions were introduced: LEED-NCv2.0 in 2001, LEED-NCv2.2 in 2005, LEED-NCv3 in 2009, and LEED-NCv4 in 2013. Although other LEED rating systems exist for Existing Buildings: Operations and Maintenance (LEED-EB), Commercial Interiors (LEED-CI), and Core and Shell Development (LEED-C \& S), LEED-NC is still one of the most requested [10]. To promote continuous LEED improvement in future versions, empirical studies analyzing building projects certified under the current LEED version appear necessary. Such studies can reveal the more successful LEED requirements that are willingly applied by project teams and the less successful requirements that have been less adopted.

In LEED-NCv2.2 [11], the total number of available points was 69 and all credits had the same weighting (1 possible point). To receive Certified, Silver, Gold, or Platinum certification, LEED-NCv2.2certified projects were required to achieve a total 26-32, 33-38, 39-51, or 52-69 points, respectively [8]. The LEED-NCv2.2 categories were: Sustainable Sites (SS), with 14 possible points; Water Efficiency (WE), with five possible points; Energy and Atmosphere (EA), with 17 possible points; Materials and Resources (MR), with 13 possible points; Indoor Environmental Quality (EQ), with 15 possible points; and Innovation and Design Process (IN), with 5 possible points. The projects certified under this version were studied by Fuerst [12] and Wu et al. [13].

Fuerst [12] analyzed over 2000 LEED-NC, LEED-CI, LEED-C \& S, and LEED-EB certified projects registered as of March 2009 in the U.S. The analyzed LEED versions were not reported by Fuerst [9]. However, according to the publishing date of this study, versions 1-2.2 were likely considered. Fuerst [12] only reported the achievements of the total number of LEED points (i.e., certification achievements), claiming that these were low. In particular, most of the projects received certification with a total number of points only slightly above the bottom thresholds for each certification level (26, 33, 39, and 52 for Certified, Silver, Gold, and Platinum, respectively).

Wu et al. [13] analyzed the category achievement of 5340 LEEDv2.2 projects around the world including the U.S., reporting varied achievements. In particular, the analysis of all projects together demonstrated that the IN category achievement was high ( $80.1 \%$ of possible points), the SS, WE, and EQ category achievements were intermediate (57.3-68.9\% of possible points), and the EA and MR category achievements were low (42.6-43.4\% of possible points). A comparison between two adjacent certification levels (Silver vs. Certified, Gold vs. Silver, and Platinum vs. Gold), i.e., cross-certification analysis, revealed that from level to level, EA category achievement increased considerably, SS and EQ category achievements showed intermediate increases, and WE, MR, and IN category achievements showed low increases.

The next version, LEED-NCv3 [14], was reshaped to include 110 points in total. As a consequence, the available points became 26, 10, 35, 14, 15, and 6 for SS, WE, EA, MR, EQ, and IN categories, respectively. Thus, the EA category, which had low achievements in projects certified under the previous LEED-NCv2.2 [13], was enhanced in LEED-NCv3, suggesting 19 possible points instead of the previous 10. However, the MR category, which also had low achievements in projects certified under LEED-NCv2.2 [13], remained the same as in the previous version. Different weights were applied to the different credits. For example, in the SS category, the Alternative transportation-public transportation access credit included six possible points, whereas Alternative transportation-low-emitting and fuel-efficient vehicles had four possible points. A new category, Regional Priority (RP) credit, 
with four bonus points, was first introduced in LEEDv3 [14] to encourage solving U.S. regional environmental issues.

The certification and category analysis of projects certified under LEED-NCv3 were extensively studied by $\mathrm{Wu}$, et al. [15] and Pushkar and Verbitsky [16,17]. Wu, et al. [15] studied 3416 LEED-NCv3 certified projects worldwide, including the U.S. The analysis of all projects together demonstrated that the SS, WE, EQ, and IN category achievements were intermediate (59.1-69.8\% of possible points), and the EA and MR category achievements were low (40.3\% and 38.7\% of possible points). The cross-certification analysis of LEED-NCv3-certified projects confirmed the results previously reported by $\mathrm{Wu}$ et al. [13] for projects certified under LEED-NCv2.2. In particular, from level to level, EA category achievement showed considerable increases, the SS and EQ category achievements showed intermediate increases, and the WE, MR, and IN category achievements showed low increases.

Pushkar and Verbitsky [16] studied 920 projects certified Silver and Gold under LEED-NCv3 in 10 states in the U.S. (California, Florida, Georgia, Illinois, Massachusetts, New York, Ohio, Texas, Virginia, and Washington) in 2016. The authors reported low certification performance: 51-55 and 61-68.5 points for Silver and Gold, respectively. They concluded that the category achievements for the Silver level confirmed the results previously reported by Wu, et al. [15]. In particular, the SS, WE, $\mathrm{EQ}$, and IN categories showed intermediate performance (56.0-68.3\% of possible points), whereas EA and MR showed low performance ( $30 \%$ and $41 \%$ of possible points, respectively).

Pushkar and Verbitsky [17] studied 1598 projects certified Silver and Gold under LEED-NCv3 in eight states in the U.S. (California, Florida, Illinois, Massachusetts, Ohio, Texas, Virginia, and Washington) in 2012-2017. The comparison analysis of Gold vs. Silver revealed that the EA category achievement showed the highest increase, the SS and EQ category achievements showed intermediate increases, and the WE, MR, and IN category achievements showed low increases, confirming the results presented by $\mathrm{Wu}$, et al. [13] for projects certified under LEED-NCv2.2.

Notably, all the aforementioned empirical studies of LEED-NCv2.2 and LEED-NCv3 analyzed the issue of certification/category/credit achievement points only, whereas Siew [18] analyzed the question of the consistency of achievement points in categories with the same level of certification (Certified, Silver, Gold or Platinum). Consequently, Siew [18], having analyzed 433 LEED-NCv2 projects from the USGBC database in 2013, concluded that the categories SS, WE, MR, IEQ and IN have inconsistent achievement points at each certification level.

The current version, LEED-NCv4 [5], includes 110 points in total, the same as LEED-NCv3. However, a new category, Integrative Process (IP), with one possible point, was added to the previous categories. The SS category (26 possible points in LEEDv3) was split in LEED-NCv4 into Location and Transportation (LT, 16 possible points) and Sustainable Site (SS, 10 possible points). The WE category was expanded in LEED-NCv4, including new requirements related to the conservation of water used for cooling towers and installation of a water consumption metering system. In LEED-NCv4, the EA category mostly remained similar to LEED-NCv3, with only an increased weight for enhanced commissioning credit (six possible points versus the two in LEED-NCv3). The MR category was reshaped in LEED-NCv4 to introduce new life-cycle-assessment-based requirements regarding building and material optimization, reuse and sourcing, and production of raw materials, building materials, and components. In general, the EQ category in LEED-NCv4 considers issues that were of concern in LEED-NCv3, with only one new credit: acoustic performance. Thus, the empirical evidence of LEED-NCv4 may differ from the empirical evidence for LEED-NCv3 reported previously by Wu et al. [15] and Pushkar and Verbitsky [16,17]. However, to the best of my knowledge, empirical evidence for LEED-NCv4 has not yet been published.

The purpose of this study was to determine the consistency of achievement points in categories and the effect size between possible points and achieved points in categories and credits in LEED-NCv4 Certified, Silver, Gold, and Platinum projects in the U.S. during 2015-2019. This is the first empirical evidence for LEED-NCv4-certified projects. This knowledge may help LEED experts to reduce 
inconsistencies and correct the currently rarely-achieved credits in next version of LEED-NC toward a proper balance in the performance of LEED categories.

\section{Materials and Methods}

\subsection{Data Collection}

In this study, projects certified in 2015-2019 according to the LEED-NCv4 [5] rating system were considered, including Certified-, Silver-, Gold-, and Platinum-awarded projects that were newly built. In total, according to the USGBC project directory (USGBC, LEED for New Construction Projects Directory [19]), 60 such projects were rated from 27 April 2015 to 16 August 2019. In particular, 22, 22, 11, and five projects received Certified, Silver, Gold, and Platinum certification, respectively. The distribution of certified projects among the states is presented in Table 1. For these projects, information from the USGBC scorecards about the points received in the IP, LT, SS, WE, EA, MR, EQ, IN, and RP categories was accumulated in an Excel database.

Table 1. Distribution of Leadership in Energy and Environmental Design (LEED)-NCv4 Certified, Silver, Gold, and Platinum projects in the U.S. in 2015-2019.

\begin{tabular}{|c|c|}
\hline Certification & State $^{1}$ (Number of Projects) \\
\hline Certified & $\begin{array}{l}\text { NC (4), MI (3), TX (3), CA (2), FL (2), CT (1), GA (1), HI (1), IN (1), NC (1), PA (1), TN (1), } \\
\text { WA (1) }\end{array}$ \\
\hline Silver & $\begin{array}{l}\text { FL (4), CO (2), MA (2), UT (2), CA (1), IA (1), ID (1), IL (1), MI (1), MO (1), MS (1), NJ (1), } \\
\mathrm{OH}(1), \mathrm{SD}(1), \mathrm{TN}(1), \mathrm{VA}(1)\end{array}$ \\
\hline Gold & CA (5), AR (1), FL (1), MA (1), OR (2), PA (1) \\
\hline Platinum & $\mathrm{CA}(2), \mathrm{CO}(1), \mathrm{MI}(1), \mathrm{VA}(1)$ \\
\hline
\end{tabular}

\subsection{Statistical Analysis}

For descriptive statistics, I used the boxplot method to evaluate LEED-NCv4 categories and the median-interquartile range (IQR, 25th-75th percentile) to evaluate LEED-NCv4 credits instead of the mean \pm standard deviation because LEED data are associated with an ordinal scale. The boxplot method calculates the median (central mark red line in the figures), the edges of the box are the 25th and 75th percentiles of IQR, the whiskers extend to the most extreme data points the algorithm considers to be not outliers, and the outliers are plotted individually (red + in the figures) [20]. The dashed black line refers the possible points for LEED-NCv4 categories. In this study, to evaluate the boxplot results, the (1) median and (2) range between lowest edges of the box/whiskers and highest edges of the box/whiskers were recognized. A wide range was judged as inconsistency in achievement points in the category and a narrow range was judged consistency in achievement points in the category points across different projects.

For inferential statistics, the nonparametric Cliff's $\delta$ effect size test was used instead of the parametric Cohen's $d$ test because the assumption of normality for LEED data was not met. Cliff's $\delta$ measures the difference magnitude between two distributions [21]. In the present study, effect size was measured between possible and achieved points in a category and credits for each certification level of LEED-NCv4 projects. Three items should be noted: (1) to perform nonparametric tests for independent groups, the minimum sample size was $\mathrm{n}_{1}=\mathrm{n}_{2}=4$ [22] (p. 19). In the present study, the minimum sample size was $n_{1}=n_{2}=5$. (2) Bergmann et al. [23] used the Wilcoxon-Mann-Whitney (WMW) nonparametric test when one of the two groups contained the same values ("somewhat unusual dataset"). In parallel, Cliff [21] noted that the WMW U statistic can be used to estimate nonparametric 
effect size. (3) I focused on substantive significance (effect size) but not statistical significance ( $p$ value) in the analysis of LEED-NCv4 projects because statistical significance depends on sample size, whereas effect size does not [24].

Cliff's $\delta$ ranged between -1 and 1 ; positive (+) values indicate that Group 1 is larger than Group 2, null (0) indicates equality or overlap, and negative (-) values indicated that Group 2 was larger than Group 1 [21]. According to Romano et al. [25], effect size is considered to be negligible if $|\delta|<0.147$, small if $0.147<|\delta|<0.33$, medium if $0.33<|\delta|<0.474$, and large if $|\delta| \geq 0.474$. In this study, to evaluate Cliff's $\delta$ effect sizes between possible and achieved points, the effect size was reformulated as the following: very high achieved points if $|\delta|<0.147$, high achieved points if $0.147<|\delta|<0.33$, medium achieved points if $0.33<|\delta|<0.474$, and low achieved points if $|\delta| \geq 0.474$. According to Cohen [26] (p. 156), a medium-achieved point effect is "visible to the naked eye of a careful observer", a low-achieved-point effect is "noticeably smaller than medium but not so small as to be trivial", and a high-achieved point's effect is "the same distance above the medium as small is below it". The effect size is not "iron-clad criteria" [27], but only a general rule of thumb can might be followed in the absence of knowledge of the area [28].

\section{Results}

\subsection{Integrative Process}

Figure 1 shows the boxplot and Cliff's $\delta$ results in the IP category. According to the boxplot, Certified, Silver, and Gold projects were within the same wide range (0-1, 0-1, and 0-1 achieved points, respectively), whereas Platinum projects had a more narrow range (0.75-1 achieved point). According to Cliff's $\delta$, the IP category showed low achievement in Certified, medium in Silver and Gold, and high in Platinum projects. This category has only one credit, which requires early analysis of the interrelationships among energy-related and water-related systems [5].

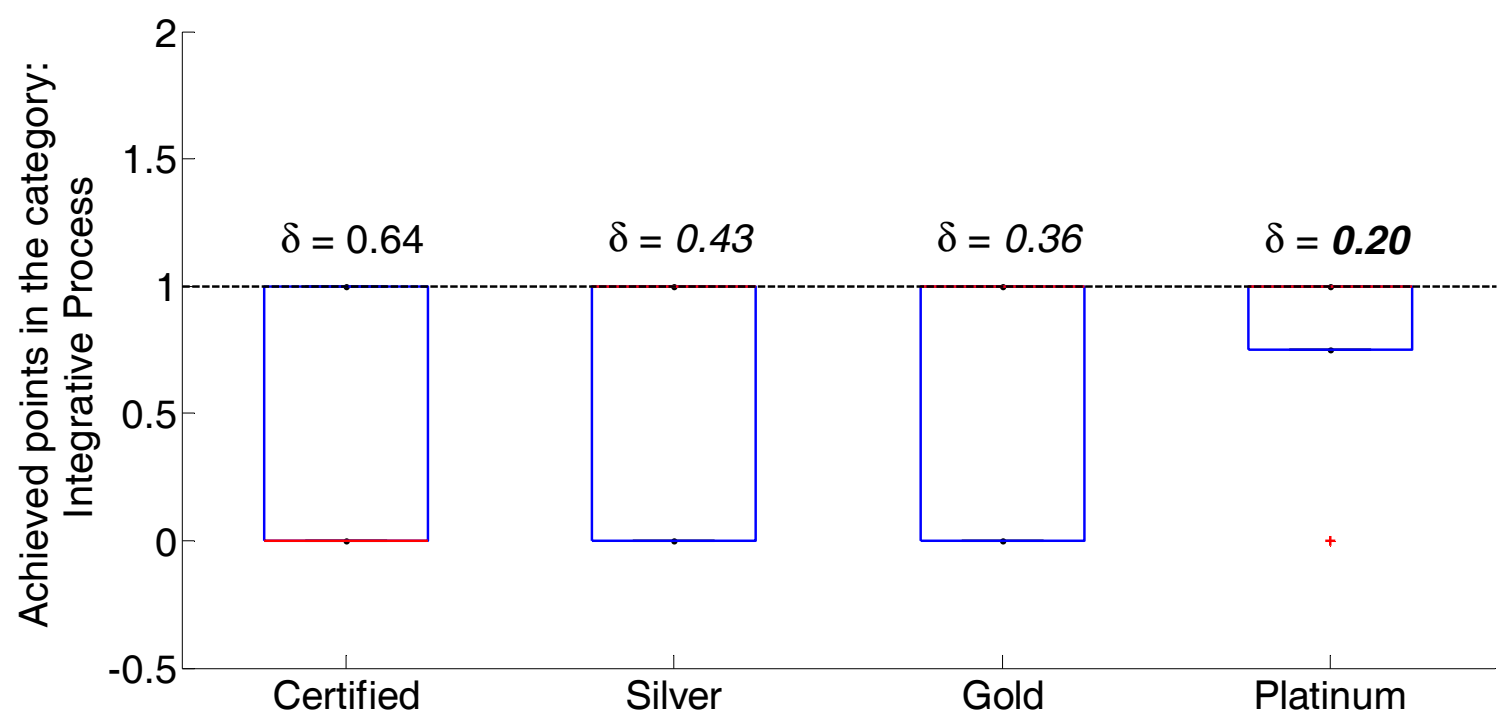

Figure 1. The boxplot results and Cliff's $\delta$ effect size between possible and achieved points in the Integrative Process (IP) category. Effect size is considered to be: very high if $|\delta|<0.147$ (bold font), high if $0.147<|\delta|<0.33$ (bold italic font), medium if $0.33<|\delta|<0.474$ (italic font), and low if $|\delta| \geq 0.474$ (normal font).

\subsection{Location and Transportation}

Figure 2 depicts the boxplot and Cliff's $\delta$ results in the LT category. According to the boxplot, the Certified, Silver, Gold, and Platinum projects were within a wide range $(0-11,1-13,5-14$, and 1-14 achieved points, respectively), whereas the median increased from level to level $(3,5,5,8$, and 9 
achieved points for Certified, Silver, Gold, and Platinum projects, respectively). According to Cliff's $\delta$, the LT category showed low achievement in all four certification levels.

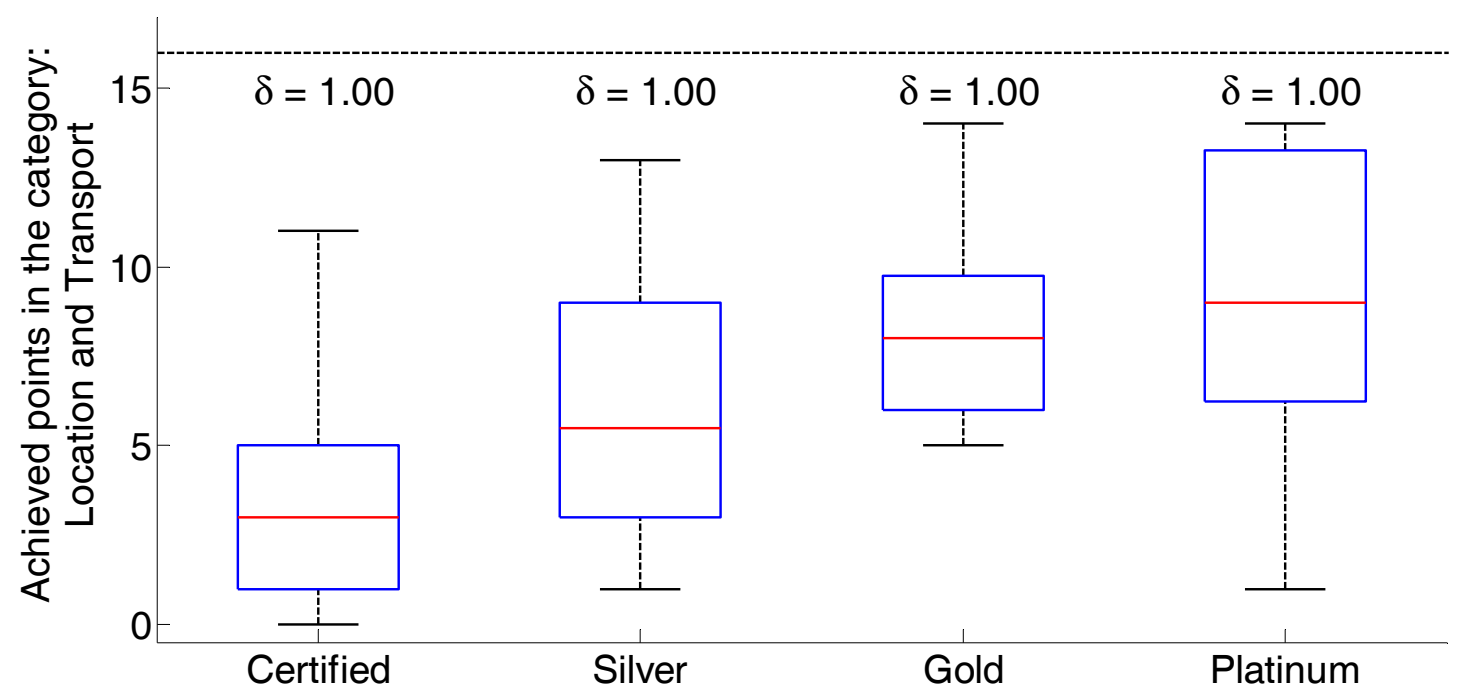

Figure 2. The boxplot results and Cliff's $\delta$ effect size between possible and achieved points in the Location and Transportation (LT) category. Effect size is considered to be: very high if $|\delta|<0.147$ (bold font), high if $0.147<|\delta|<0.33$ (bold italic font), medium if $0.33<|\delta|<0.474$ (italic font), and low if $|\delta| \geq 0.474$ (normal font).

Table 2 provides median \pm IQR (25th-75th) and Cliff's $\delta$ results for LT credits. In four certification levels, six of the eight LT credits have similar Cliff's $\delta$ effect sizes between possible and achieved points. The LEED credits for Neighborhood development location, High-priority site, Surrounding density, Access to quality transit, and Green vehicles showed low achievement, whereas the Sensitive land protection credit had high or very high achievement.

Table 2. Credit points achieved for Location and Transportation category of LEED-NCv4 projects: median \pm interquartile range (IQR, 25th-75th) and Cliff's $\delta$ effect size of differences between possible and achieved points in a credit.

\begin{tabular}{|c|c|c|c|c|c|}
\hline \multirow{2}{*}{ Credit } & \multirow{2}{*}{$\begin{array}{l}\text { Possible } \\
\text { Points }\end{array}$} & \multicolumn{4}{|c|}{ Achieved Points } \\
\hline & & Certified & Silver & Gold & Platinum \\
\hline $\begin{array}{l}\text { LEED for neighborhood } \\
\text { development location }\end{array}$ & 16 & $\begin{array}{l}0.0 \pm 0.0 \\
1.00\end{array}$ & $\begin{array}{c}0.0 \pm 0.0 \\
1.00\end{array}$ & $\begin{array}{l}0.0 \pm 0.0 \\
1.00\end{array}$ & $\begin{array}{c}0.0 \pm 0.0 \\
1.00\end{array}$ \\
\hline Sensitive land protection & 1 & $\begin{array}{l}1.0 \pm 1.0 \\
\mathbf{0 . 2 7}\end{array}$ & $\begin{array}{c}1.0 \pm 0.0 \\
\mathbf{0 . 1 8}\end{array}$ & $\begin{array}{l}1.0 \pm 0.0 \\
\mathbf{0 . 0 0}\end{array}$ & $\begin{array}{c}1.0 \pm 0.3 \\
\mathbf{0 . 2 0}\end{array}$ \\
\hline High-priority site & 2 & $\begin{array}{l}0.0 \pm 0.0 \\
0.95\end{array}$ & $\begin{array}{c}0.0 \pm 1.0 \\
0.82\end{array}$ & $\begin{array}{l}0.0 \pm 1.8 \\
0.73\end{array}$ & $\begin{array}{c}0.0 \pm 1.0 \\
1.00\end{array}$ \\
\hline $\begin{array}{l}\text { Surrounding density and } \\
\text { diverse uses }\end{array}$ & 5 & $\begin{array}{l}1.0 \pm 2.0 \\
0.95\end{array}$ & $\begin{array}{c}2.0 \pm 1.0 \\
0.86\end{array}$ & $\begin{array}{l}2.0 \pm 2.8 \\
0.73\end{array}$ & $\begin{array}{c}2.0 \pm 3.5 \\
0.60\end{array}$ \\
\hline Access to quality transit & 5 & $\begin{array}{l}0.0 \pm 1.0 \\
0.91\end{array}$ & $\begin{array}{c}0.0 \pm 3.0 \\
0.95\end{array}$ & $\begin{array}{c}3.0 \pm 3.8 \\
0.91\end{array}$ & $\begin{array}{c}4.0 \pm 2.8 \\
0.60\end{array}$ \\
\hline Bicycle facilities & 1 & $\begin{array}{l}0.0 \pm 0.0 \\
0.82\end{array}$ & $\begin{array}{c}0.5 \pm 1.0 \\
0.50\end{array}$ & $\begin{array}{l}1.0 \pm 1.0 \\
0.45\end{array}$ & $\begin{array}{c}1.0 \pm 1.0 \\
0.40\end{array}$ \\
\hline $\begin{array}{l}\text { Reduced parking } \\
\text { footprint }\end{array}$ & 1 & $\begin{array}{l}0.0 \pm 1.0 \\
0.64\end{array}$ & $\begin{array}{c}1.0 \pm 1.0 \\
0.41\end{array}$ & $\begin{array}{l}0.0 \pm 1.0 \\
0.45\end{array}$ & $\begin{array}{c}1.0 \pm 1.0 \\
0.40\end{array}$ \\
\hline Green vehicles & 1 & $\begin{array}{l}0.0 \pm 0.0 \\
0.77\end{array}$ & $\begin{array}{c}0.0 \pm 1.0 \\
0.64\end{array}$ & $\begin{array}{l}0.0 \pm 1.0 \\
0.55\end{array}$ & $\begin{array}{c}0.0 \pm 1.0 \\
0.60\end{array}$ \\
\hline
\end{tabular}

Notes: Effect size is considered to be: very high if $|\delta|<0.147$ (bold font), high if $0.147<|\delta|<0.33$ (bold italic font), medium if $0.33<|\delta|<0.474$ (italic font), and low if $|\delta| \geq 0.474$ (normal font). 
Among the low-achieved credits, LEED for Neighborhood development location requires location of the project near a development that was already certified under LEED for neighborhood development [5]. This was not possible for the projects analyzed in this study. Two other low-achieved location credits, High-priority site and Surrounding density and diverse uses, restrict the project location to certain areas, such as contaminated areas and areas with existing infrastructure, respectively. The next two rarely achieved transportation credits, Access to quality transit and Green vehicles, require close vicinity to public transportation and installation of additional alternative electric or gas fueling facilities, respectively [5].

Only two of the eight LT credits have different Cliff's $\delta$ effect sizes between possible and achieved points at the different certification levels (Table 2). The Bicycle facilities credit showed low achievement in Certified and Silver projects and medium in Gold and Platinum projects. The Reduced parking footprint credit showed low achievement in Certified projects and medium in Silver, Gold, and Platinum projects.

\subsection{Sustainable Sites}

Figure 3 shows the boxplot and Cliff's $\delta$ results in SS category. According to the boxplot, the median increased from level to level $(2.5,4,5$, and 5 achieved points in Certified, Silver, Gold, and Platinum projects, respectively) with decreasing in the range from level to level $(1-8,1-7,3-6$, and 5-8 achieved points in Certified, Silver, Gold, and Platinum projects, respectively). According to Cliff's $\delta$, the SS category showed low achievement in all four certification levels.

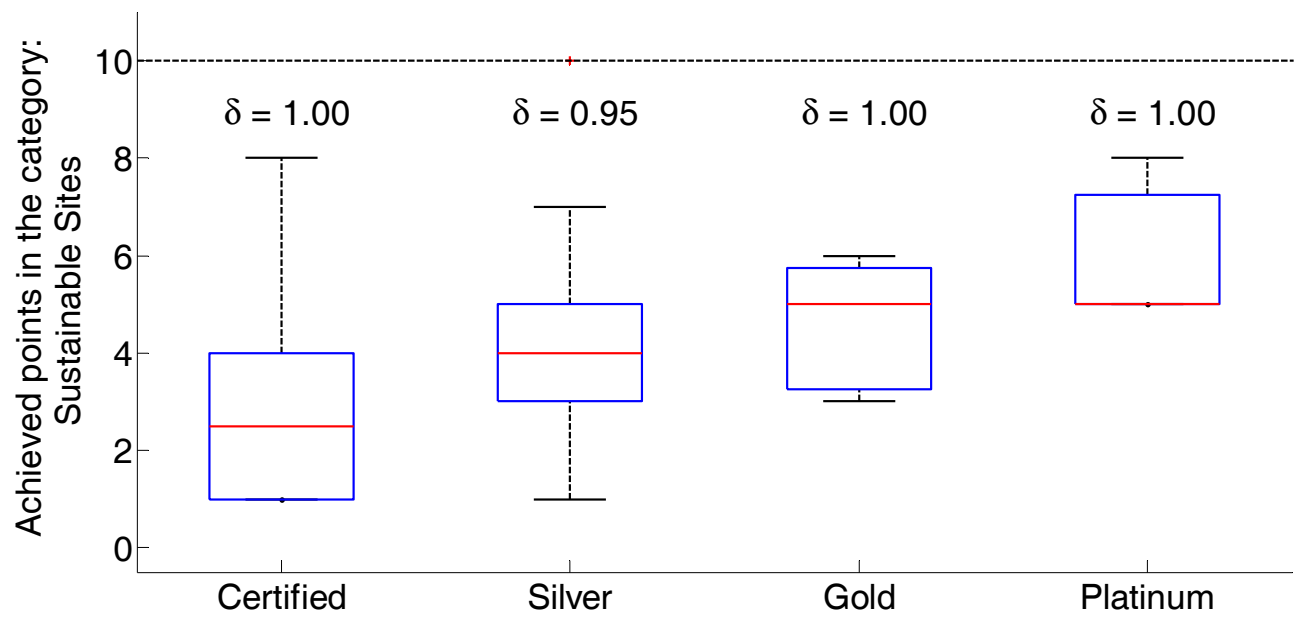

Figure 3. The boxplot results and Cliff's $\delta$ effect size between possible and achieved points in the Sustainable Sites (SS) category. Effect size is considered to be: very high if $|\delta|<0.147$ (bold font), high if $0.147<|\delta|<0.33$ (bold italic font), medium if $0.33<|\delta|<0.474$ (italic font), and low if $|\delta| \geq 0.474$ (normal font).

Table 3 shows median \pm IQR (25th-75th) and Cliff's $\delta$ results for SS credits. In four certification levels, two of the six SS credits have similar Cliff's $\delta$ effect sizes between possible and achieved points. The Site development-protect or restore habitat and Rainwater management credits had low achievement for four certification levels. The Site development-protect or restore habitat credit aims to preserve $40 \%$ of the greenfield area on the site [5], and these areas appeared to be unavailable in the projects analyzed in this study. Rainwater management requires the implementation of water management infrastructure [5], thereby increasing project costs.

Four of the six SS credits have different Cliff's $\delta$ effect sizes between possible and achieved points in different certification levels (Table 3). Achievement of Site assessment, Open space, Heat island reduction, and Light pollution reduction credits gradually increased from low and medium in Certified projects through medium and high in Silver/Gold projects to high and very high in Gold/Platinum projects. 
Table 3. Credit points achieved for Sustainable Sites (SS) category of LEED-NCv4 projects: median \pm IQR (25th-75th) and Cliff's $\delta$ effect size between possible and achieved points in a credit.

\begin{tabular}{|c|c|c|c|c|c|}
\hline \multirow{2}{*}{ Credit } & \multirow{2}{*}{$\begin{array}{l}\text { Possible } \\
\text { Points }\end{array}$} & \multicolumn{4}{|c|}{ Achieved Points } \\
\hline & & Certified & Silver & Gold & Platinum \\
\hline Site assessment & 1 & $\begin{array}{l}0.5 \pm 1.0 \\
0.50\end{array}$ & $\begin{array}{l}1.0 \pm 1.0 \\
0.32\end{array}$ & $\begin{array}{l}1.0 \pm 0.0 \\
0.18\end{array}$ & $\begin{array}{c}1.0 \pm 0.0 \\
\mathbf{0 . 0 0}\end{array}$ \\
\hline $\begin{array}{l}\text { Site development-protect or } \\
\text { restore habitat }\end{array}$ & 2 & $\begin{array}{l}0.0 \pm 0.0 \\
0.91\end{array}$ & $\begin{array}{l}0.0 \pm 0.0 \\
0.86\end{array}$ & $\begin{array}{l}0.0 \pm 0.0 \\
1.00\end{array}$ & $\begin{array}{c}1.0 \pm 2.0 \\
0.60\end{array}$ \\
\hline Open space & 1 & $\begin{array}{l}0.0 \pm 0.0 \\
0.77\end{array}$ & $\begin{array}{l}0.5 \pm 1.0 \\
0.50\end{array}$ & $\begin{array}{l}0.0 \pm 1.0 \\
0.55\end{array}$ & $\begin{array}{c}1.0 \pm 0.3 \\
0.20\end{array}$ \\
\hline Rainwater management & 3 & $\begin{array}{l}0.0 \pm 0.0 \\
0.86\end{array}$ & $\begin{array}{l}0.0 \pm 2.0 \\
0.77\end{array}$ & $\begin{array}{l}0.0 \pm 2.0 \\
0.82\end{array}$ & $\begin{array}{c}0.0 \pm 0.8 \\
0.80\end{array}$ \\
\hline Heat island reduction & 2 & $\begin{array}{l}0.0 \pm 2.0 \\
0.64\end{array}$ & $\begin{array}{l}2.0 \pm 2.0 \\
0.32\end{array}$ & $\begin{array}{l}2.0 \pm 0.0 \\
0.09\end{array}$ & $\begin{array}{c}2.0 \pm 0.5 \\
0.20\end{array}$ \\
\hline Light pollution reduction & 1 & $\begin{array}{l}1.0 \pm 1.0 \\
0.41\end{array}$ & $\begin{array}{l}1.0 \pm 0.0 \\
0.23\end{array}$ & $\begin{array}{l}1.0 \pm 1.0 \\
0.45\end{array}$ & $\begin{array}{c}1.0 \pm 0.0 \\
\mathbf{0 . 0 0}\end{array}$ \\
\hline
\end{tabular}

Notes: Effect size is considered to be: very high if $|\delta|<0.147$ (bold font), high if $0.147<|\delta|<0.33$ (bold italic font), medium if $0.33<|\delta|<0.474$ (italic font), and low if $|\delta| \geq 0.474$ (normal font).

\subsection{Water Efficiency}

Figure 4 shows the boxplot and Cliff's $\delta$ results in the WE category. According to the boxplot, the range was wide in Certified, Silver, and Gold projects (3-8, 2-9, and 2-8 achieved points, respectively) and narrow in Platinum projects (7-10 achieved points). The median increased from five achieved points in Certified and Silver to six and eight achieved points in Gold and Platinum, respectively. According to Cliff's $\delta$, the WE category showed low achievement in all four certification levels.

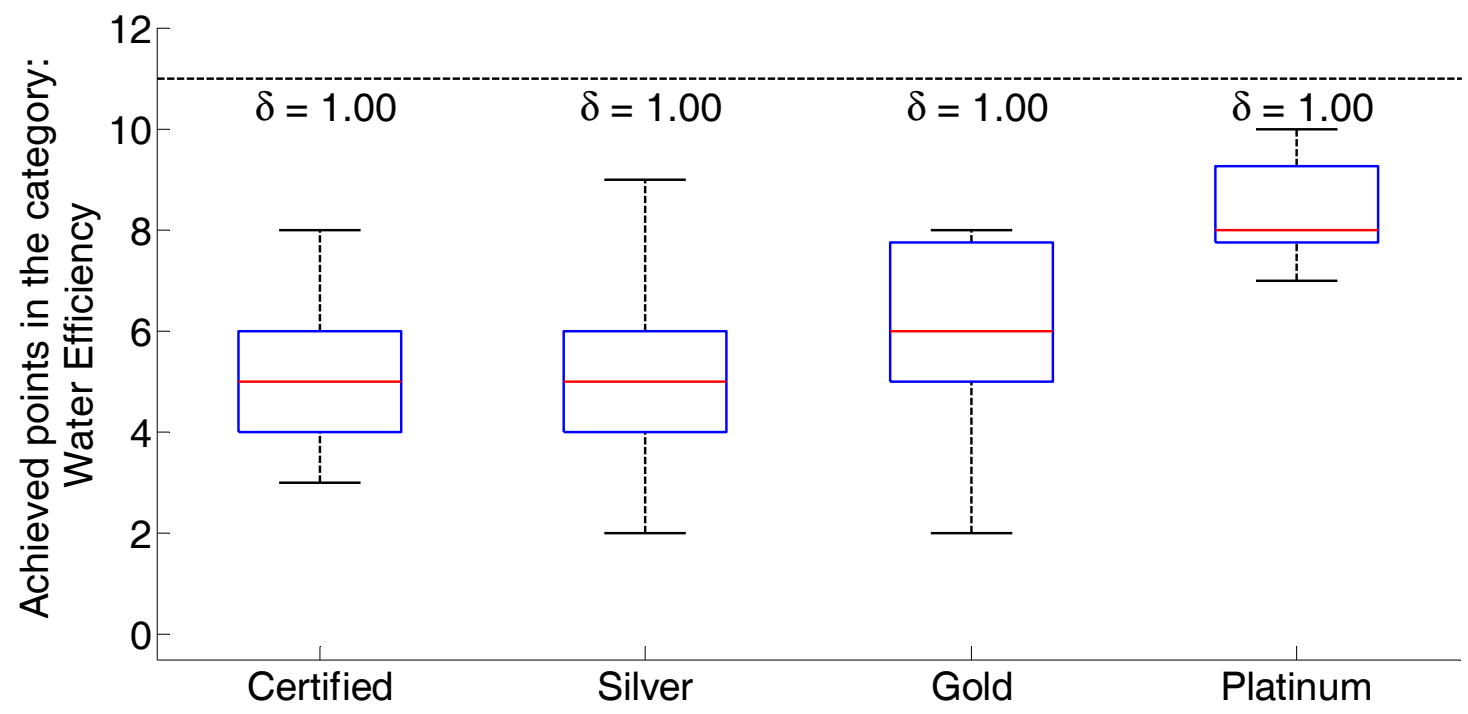

Figure 4. The boxplot results and Cliff's $\delta$ effect size between possible and achieved points in the Water Efficiency (WE) category. Effect size is considered to be: very high if $|\delta|<0.147$ (bold font), high if $0.147<|\delta|<0.33$ (bold italic font), medium if $0.33<|\delta|<0.474$ (italic font), and low if $|\delta| \geq 0.474$ (normal font).

Table 4 shows median \pm IQR (25th-75th) and Cliff's $\delta$ results in WE credits. In four certification levels, two of the four WE credits had similar Cliff's $\delta$ effect sizes between possible and achieved points. Cooling tower water use and Indoor water use reduction credits showed low achievement in 
all four levels of certification. Cooling tower water use requires the conservation of water used for a cooling tower, and Indoor water use reduction requires installing equipment that allows potable water reduction [5].

Table 4. Credit points achieved for Water Efficiency category of LEED-NCv4 projects: median \pm IQR (25th-75th) and Cliff's $\delta$ effect size between possible and achieved points in a credit.

\begin{tabular}{lccccc}
\hline \multirow{2}{*}{ Credit } & \multirow{2}{*}{$\begin{array}{c}\text { Possible } \\
\text { Points }\end{array}$} & Certified & Silver & Gold & Platinum \\
\cline { 3 - 6 } & \multirow{2}{*}{2} & $0.0 \pm 0.0$ & $0.0 \pm 0.0$ & $0.0 \pm 0.0$ & $0.0 \pm 1.0$ \\
Cooling tower & 1.00 & 0.91 & 0.91 & 1.00 \\
water use & \multirow{2}{*}{$1.0 \pm 1.0$} & $1.0 \pm 1.0$ & $1.0 \pm 1.0$ & $1.0 \pm 0.0$ \\
\hline Water metering & 0.45 & 0.41 & 0.36 & $\mathbf{0 . 0 0}$ \\
\hline Outdoor water & \multirow{2}{*}{2} & $2.0 \pm 1.0$ & $2.0 \pm 1.0$ & $1.0 \pm 1.0$ & $2.0 \pm 0.3$ \\
use reduction & & 0.34 & 0.45 & 0.45 & $\mathbf{0 . 2 0}$ \\
\hline Indoor water & \multirow{2}{*}{6} & $3.0 \pm 2.0$ & $3.0 \pm 2.0$ & $3.0 \pm 2.0$ & $5.0 \pm 1.3$ \\
use reduction & & 0.91 & 1.00 & 0.82 & 0.60 \\
\hline
\end{tabular}

Notes: Effect size is considered to be: very high if $|\delta|<0.147$ (bold font), high if $0.147<|\delta|<0.33$ (bold italic font), medium if $0.33<|\delta|<0.474$ (italic font), and low if $|\delta| \geq 0.474$ (normal font).

Two other WE credits had different Cliff's $\delta$ effect sizes between possible and achieved points in different certification levels (Table 4). Water metering and Outdoor water use reduction credits showed medium achievement in Certified, Silver, and Gold projects and very high or high in Platinum projects.

\subsection{Energy and Atmosphere}

Figure 5 demonstrates the Boxplot and Cliff's $\delta$ results in EA category. According to the boxplot, the median increased from Certified, Silver, and Gold (19, 18, and 22 achieved points, respectively) to Platinum (32 achieved points), with decrease in the range from Certified, Silver, and Gold (6-25, 9-27, and 17-29 achieved points, respectively) to Platinum with 27-33 achieved points. According to Cliff's $\delta$, the EA category showed low achievement in all four certification levels.

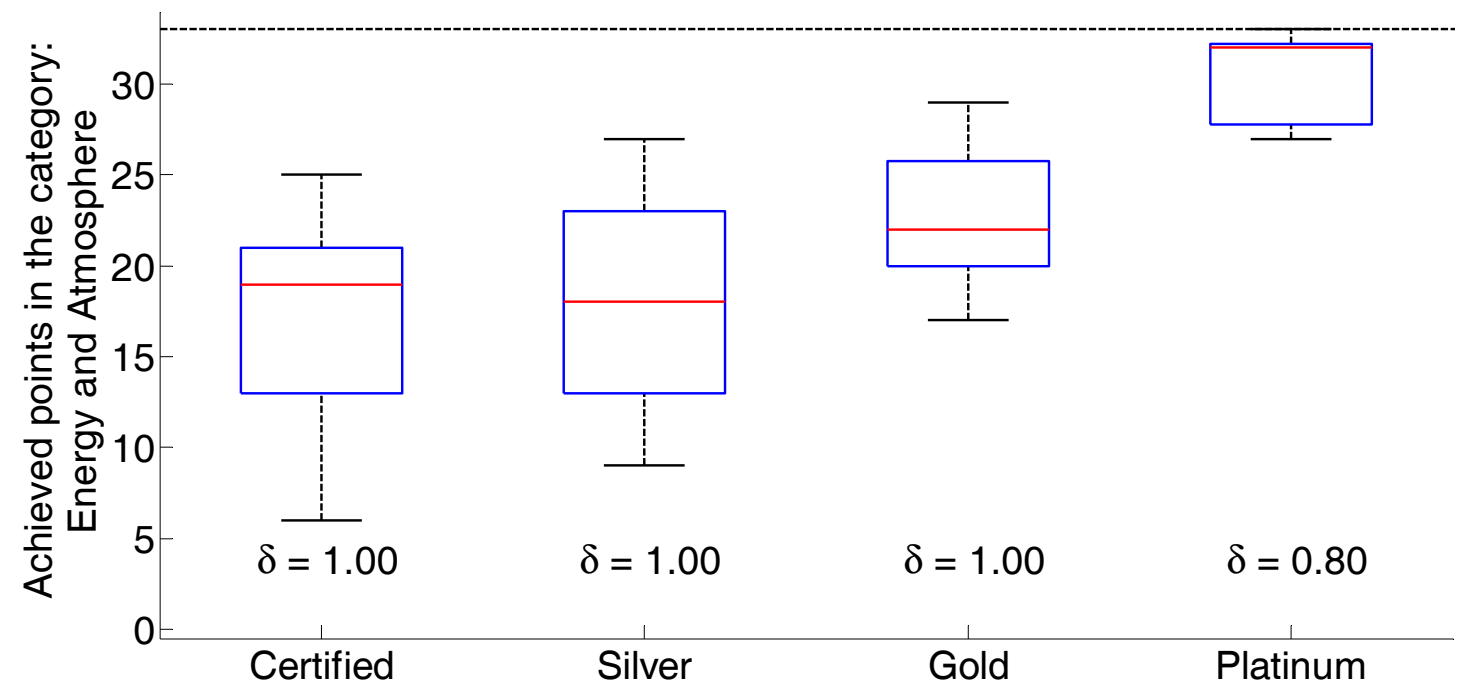

Figure 5. The boxplot results and Cliff's $\delta$ effect size between possible and achieved points in the Energy and Atmosphere category. Effect size is considered to be: very high if $|\delta|<0.147$ (bold font), high if $0.147<|\delta|<0.33$ (bold italic font), medium if $0.33<|\delta|<0.474$ (italic font), and low if $|\delta| \geq 0.474$ (normal font). 
Table 5 shows median \pm IQR (25th-75th) and Cliff's $\delta$ results in EA credits. In four certification levels, three of the seven EA credits had similar Cliff's $\delta$ effect sizes between possible and achieved points. Enhanced commissioning, Demand response, and Enhanced refrigerant management credits showed low achievement in all four certification levels. Enhanced commissioning refers to the completion of commissioning processes for mechanical, electrical, plumbing, and renewable energy systems; Demand response requires installation of automated systems for energy-related equipment; and Enhanced refrigerant management is related to prohibiting refrigerants or using special low-impact refrigerants [5].

Table 5. Credit points achieved for Energy and Atmosphere category of LEED-NCv4 projects: median \pm IQR (25th-75th) and Cliff's $\delta$ effect size between possible and achieved points in a credit.

\begin{tabular}{|c|c|c|c|c|c|}
\hline \multirow{2}{*}{ Credit } & \multirow{2}{*}{$\begin{array}{l}\text { Possible } \\
\text { Points }\end{array}$} & \multicolumn{4}{|c|}{ Achieved Points } \\
\hline & & Certified & Silver & Gold & Platinum \\
\hline $\begin{array}{c}\text { Enhanced } \\
\text { commissioning }\end{array}$ & 6 & $\begin{array}{c}3.0 \pm 3.0 \\
0.86\end{array}$ & $\begin{array}{c}4.0 \pm 2.0 \\
0.91\end{array}$ & $\begin{array}{c}4.0 \pm 2.0 \\
0.91\end{array}$ & $\begin{array}{c}6.0 \pm 3.3 \\
0.48\end{array}$ \\
\hline $\begin{array}{l}\text { Advanced energy } \\
\text { metering }\end{array}$ & 1 & $\begin{array}{l}0.0 \pm 1.0 \\
0.64\end{array}$ & $\begin{array}{c}1.0 \pm 1.0 \\
0.41\end{array}$ & $\begin{array}{l}1.0 \pm 1.0 \\
0.45\end{array}$ & $\begin{array}{l}1.0 \pm 0.0 \\
\mathbf{0 . 0 0}\end{array}$ \\
\hline Demand response & 2 & $\begin{array}{l}0.0 \pm 0.0 \\
1.00\end{array}$ & $\begin{array}{l}0.0 \pm 0.0 \\
0.95\end{array}$ & $\begin{array}{l}0.0 \pm 0.0 \\
0.91\end{array}$ & $\begin{array}{c}1.0 \pm 2.0 \\
0.60\end{array}$ \\
\hline $\begin{array}{l}\text { Renewable energy } \\
\text { production }\end{array}$ & 3 & $\begin{array}{l}0.0 \pm 2.0 \\
0.73\end{array}$ & $\begin{array}{l}0.0 \pm 2.0 \\
0.77\end{array}$ & $\begin{array}{c}3.0 \pm 2.8 \\
0.36\end{array}$ & $\begin{array}{l}3.0 \pm 0.0 \\
\mathbf{0 . 0 0}\end{array}$ \\
\hline $\begin{array}{c}\text { Enhanced refrigerant } \\
\text { management }\end{array}$ & 1 & $\begin{array}{l}0.0 \pm 1.0 \\
0.64\end{array}$ & $\begin{array}{l}0.5 \pm 1.0 \\
0.50\end{array}$ & $\begin{array}{l}1.0 \pm 1.0 \\
0.45\end{array}$ & $\begin{array}{l}0.0 \pm 1.0 \\
0.60\end{array}$ \\
\hline $\begin{array}{c}\text { Green power and carbon } \\
\text { offsets }\end{array}$ & 2 & $\begin{array}{c}0.0 \pm 1.0 \\
0.77\end{array}$ & $\begin{array}{c}0.0 \pm 2.0 \\
0.59\end{array}$ & $\begin{array}{l}2.0 \pm 2.0 \\
0.45\end{array}$ & $\begin{array}{l}2.0 \pm 0.0 \\
\mathbf{0 . 0 0}\end{array}$ \\
\hline $\begin{array}{l}\text { Optimize energy } \\
\text { performance }\end{array}$ & 18 & $\begin{array}{c}13.0 \pm 8.0 \\
0.82\end{array}$ & $\begin{array}{l}11.5 \pm 9.0 \\
0.82\end{array}$ & $\begin{array}{l}17.0 \pm 6.3 \\
0.64\end{array}$ & $\begin{array}{c}18.0 \pm 0.0 \\
\mathbf{0 . 0 0}\end{array}$ \\
\hline
\end{tabular}

Notes: Effect size is considered to be: very high if $|\delta|<0.147$ (bold font), high if $0.147<|\delta|<0.33$ (bold italic font), medium if $0.33<|\delta|<0.474$ (italic font), and low if $|\delta| \geq 0.474$ (normal font).

Four other EA credits had different Cliff's $\delta$ effect sizes between possible and achieved points in different certification levels (Table 5). Advanced energy metering credit gradually increased from low achievement in Certified projects through medium in Silver and Gold projects to very high in Platinum projects. Renewable energy production and Green power and carbon offsets credits showed low achievement in Certified and Silver projects, medium in Gold projects, and very high in Platinum projects. The Optimize energy performance credit had low achievement in Certified, Silver, and Gold projects and very high in Platinum projects.

\subsection{Materials and Resources}

Figure 6 depicts the boxplot and Cliff's $\delta$ results in the MR category. According to the boxplot, the range was wide in all four certification levels $(0-7,0-8,2-7$, and 4-9 achieved points in Certified, Silver, Gold, and Platinum projects, respectively), whereas the median increased from level to level $(2,3,4$, and 7 achieved points in Certified, Silver, Gold, and Platinum, respectively). According to Cliff's $\delta$, the MR category showed low achievement in all four certification levels.

Table 6 provides the median \pm IQR (25th-75th) and Cliff's $\delta$ results in MR credits. In all four certification levels, all MR credits have similar Cliff's $\delta$ effect sizes between possible and achieved points. Building life-cycle impact reduction, Building product disclosure and optimization (BPD \& O)-environmental product declarations, BPD \& O-sourcing of raw materials, and BPD \& O-material ingredients credits showed low achievement for each level of certification. The Building life-cycle impact credit requires performing a life cycle assessment (LCA) of the whole building [5], which can be 
costly due to requiring LCA-related consultants, software tools, and datasets. Three other credits, BPD \& O-Environmental product declarations, BPD \& O-sourcing of raw materials, and BPD \& O-material ingredients, also require the use of products and materials with available LCA [5]. In contrast with these low-achieved credits, Construction and demolition waste management had high or very high achievement in each level of certification.

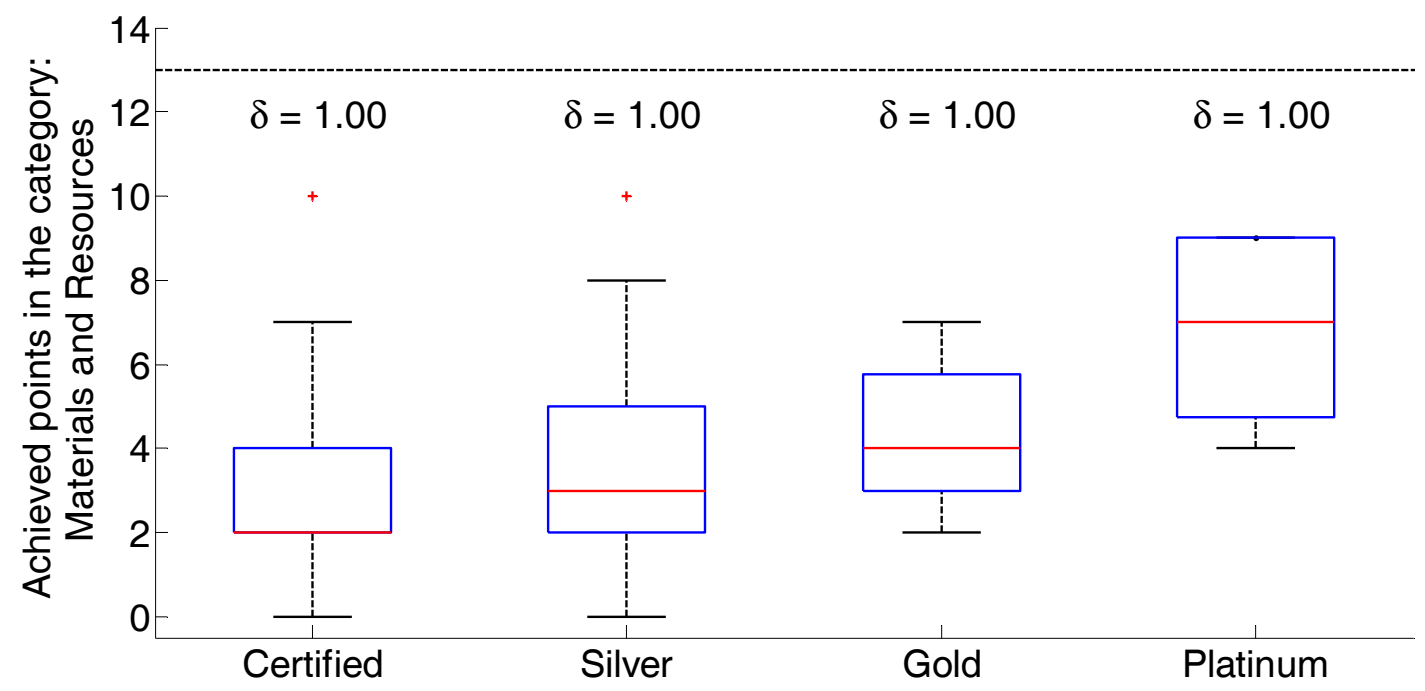

Figure 6. The boxplot results and Cliff's $\delta$ effect size between possible and achieved points in the Materials and Resources (MR) category. Effect size is considered to be: very high if $|\delta|<0.147$ (bold font), high if $0.147<|\delta|<0.33$ (bold italic font), medium if $0.33<|\delta|<0.474$ (italic font), and low if $|\delta| \geq$ 0.474 (normal font).

Table 6. Credit points achieved for Materials and Resources category of LEED-NCv4 projects: median \pm IQR (25th-75th) and Cliff's $\delta$ effect size between possible and achieved points in a credit.

\begin{tabular}{|c|c|c|c|c|c|}
\hline \multirow{2}{*}{ Credit } & \multirow{2}{*}{$\begin{array}{l}\text { Possible } \\
\text { Points }\end{array}$} & \multicolumn{4}{|c|}{ Achieved Points } \\
\hline & & Certified & Silver & Gold & Platinum \\
\hline $\begin{array}{l}\text { Building life-cycle impact } \\
\text { reduction }\end{array}$ & 5 & $\begin{array}{l}0.0 \pm 0.0 \\
0.91\end{array}$ & $\begin{array}{c}0.0 \pm 2.0 \\
0.95\end{array}$ & $\begin{array}{c}0.0 \pm 2.8 \\
0.91\end{array}$ & $\begin{array}{c}3.0 \pm 0.8 \\
1.00\end{array}$ \\
\hline $\begin{array}{l}\text { BPD \& O-environmental } \\
\text { product declarations }\end{array}$ & 2 & $\begin{array}{l}0.0 \pm 1.0 \\
1.00\end{array}$ & $\begin{array}{c}1.0 \pm 1.0 \\
1.00\end{array}$ & $\begin{array}{l}1.0 \pm 1.0 \\
1.00\end{array}$ & $\begin{array}{c}1.0 \pm 0.3 \\
1.00\end{array}$ \\
\hline $\begin{array}{c}\text { BPD \& O-sourcing of raw } \\
\text { materials }\end{array}$ & 2 & $\begin{array}{c}0.0 \pm 0.0 \\
1.00\end{array}$ & $\begin{array}{c}0.0 \pm 0.0 \\
1.00\end{array}$ & $\begin{array}{c}0.0 \pm 0.8 \\
1.00\end{array}$ & $\begin{array}{c}1.0 \pm 1.3 \\
0.60\end{array}$ \\
\hline BPD \& O-material ingredients & 2 & $\begin{array}{l}0.0 \pm 0.0 \\
1.00\end{array}$ & $\begin{array}{c}0.0 \pm 1.0 \\
1.00\end{array}$ & $\begin{array}{l}0.0 \pm 1.0 \\
1.00\end{array}$ & $\begin{array}{c}1.0 \pm 1.0 \\
1.00\end{array}$ \\
\hline $\begin{array}{c}\text { Construction and demolition } \\
\text { waste management }\end{array}$ & 2 & $\begin{array}{c}2.0 \pm 0.0 \\
0.23\end{array}$ & $\begin{array}{c}2.0 \pm 0.0 \\
\mathbf{0 . 1 4}\end{array}$ & $\begin{array}{c}2.0 \pm 0.8 \\
0.27\end{array}$ & $\begin{array}{c}2.0 \pm 0.3 \\
0.20\end{array}$ \\
\hline
\end{tabular}

Notes: Effect size is considered to be: very high if $|\delta|<0.147$ (bold font), high if $0.147<|\delta|<0.33$ (bold italic font), medium if $0.33<|\delta|<0.474$ (italic font), and low if $|\delta| \geq 0.474$ (normal font).

\subsection{Indoor Environmental Quality}

Figure 7 shows the boxplot and Cliff's $\delta$ results in the EQ category. According to the boxplot, the median increased from Certified through Silver and Gold to Platinum $(5,7,7$, and 9 achieved points, respectively) with approximately the same wide range in Certified, Silver, Gold, and Platinum (1-9, 2-10, 4-8, and 7-13 achieved points, respectively). According to Cliff's $\delta$, the EQ category demonstrated low achievement in all four certification levels. 


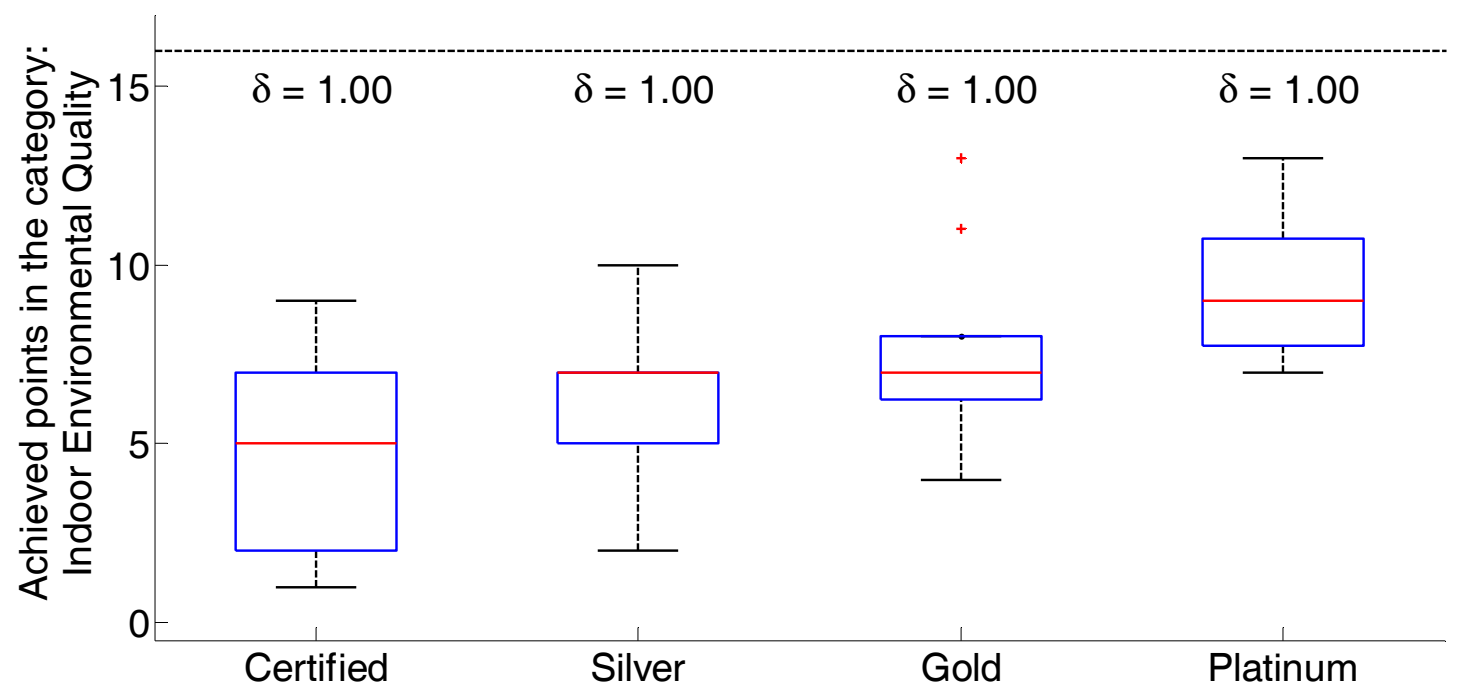

Figure 7. Boxplot results and Cliff's $\delta$ effect size between possible and achieved points in the Indoor Environmental Quality (EQ) category. Effect size is considered to be: very high if $|\delta|<0.147$ (bold font), high if $0.147<|\delta|<0.33$ (bold italic font), medium if $0.33<|\delta|<0.474$ (italic font), and low if $|\delta| \geq 0.474$ (normal font).

Table 7 provides median \pm IQR (25th-75th) and Cliff's $\delta$ results for EQ credits. In the four certification levels, five of the nine EQ credits had similar Cliff's $\delta$ effect sizes between possible and achieved points. Among these credits, only the Construction indoor air quality management credit had high or very high achievement, whereas the Low-emitting materials, Indoor air quality assessment, Daylight, and Acoustic performance credits had low achievement in each level of certification. Low-emitting materials requires the use of special interior materials and products such as paint, coverings, flooring, and furniture with low volatile organic compound (VOC) emissions [5], which might increase the project budget. Indoor air quality assessment requires cleaning the indoor air in buildings after construction and during occupancy. Daylight credit is related to window area, which can be restricted by other design requirements, such as an esthetics. Acoustic performance requires restricting background noise levels of mechanical systems [5].

Four other EQ credits had different Cliff's $\delta$ effect sizes between possible and achieved points in the different certification levels (Table 7). Enhanced indoor air quality had low achievement in Certified and Silver projects and medium in Gold and Platinum projects. Thermal comfort and Interior lighting had low achievement in Certified, Silver, and Gold projects, and high or very high in Platinum projects. The Quality views credit gradually increased from low-achieved in Certified and Silver projects to medium in Gold projects and high in Platinum projects. Enhanced indoor air quality requires increased ventilation rates and installation of filtration systems [5]. Thermal comfort requires localized thermal comfort strategies with increased space for plumbing; heating, ventilation, and air conditioning (HVAC) equipment; and cable equipment [5], which can be restricted by the design of the interior areas. Interior lighting requires providing individual lighting controls as well as special light sources with a high color-rendering index [5], which may increase the project budget. Quality views is related to window area [5], which can be restricted by other design requirements, such as an esthetics. Therefore, only projects certified Platinum attempted to receive the maximum possible points for these credits. 
Table 7. Credit points achieved for Indoor Environmental Quality (EQ) category of LEED-NCv4 projects: median \pm IQR (25th-75th) and Cliff's $\delta$ effect size between possible and achieved points in a credit.

\begin{tabular}{|c|c|c|c|c|c|}
\hline \multirow{2}{*}{ Credit } & \multirow{2}{*}{$\begin{array}{l}\text { Possible } \\
\text { Points }\end{array}$} & \multicolumn{4}{|c|}{ Achieved Points } \\
\hline & & Certified & Silver & Gold & Platinum \\
\hline $\begin{array}{l}\text { Enhanced indoor air } \\
\text { quality strategies }\end{array}$ & 2 & $\begin{array}{c}1.0 \pm 2.0 \\
0.64\end{array}$ & $\begin{array}{c}1.5 \pm 1.0 \\
0.50\end{array}$ & $\begin{array}{l}2.0 \pm 1.8 \\
0.45\end{array}$ & $\begin{array}{c}2.0 \pm 2.0 \\
0.40\end{array}$ \\
\hline Low-emitting materials & 3 & $\begin{array}{l}0.0 \pm 1.0 \\
0.82\end{array}$ & $\begin{array}{c}1.0 \pm 2.0 \\
0.86\end{array}$ & $\begin{array}{c}1.0 \pm 1.8 \\
0.73\end{array}$ & $\begin{array}{c}2.0 \pm 1.3 \\
0.80\end{array}$ \\
\hline $\begin{array}{l}\text { Construction indoor air } \\
\text { quality management plan }\end{array}$ & 1 & $\begin{array}{c}1.0 \pm 1.0 \\
0.32\end{array}$ & $\begin{array}{c}1.0 \pm 0.0 \\
\mathbf{0 . 0 0}\end{array}$ & $\begin{array}{c}1.0 \pm 0.0 \\
0.09\end{array}$ & $\begin{array}{c}1.0 \pm 0.0 \\
\mathbf{0 . 0 0}\end{array}$ \\
\hline Indoor air quality assessment & 2 & $\begin{array}{c}0.0 \pm 1.0 \\
0.86\end{array}$ & $\begin{array}{c}0.0 \pm 2.0 \\
0.73\end{array}$ & $\begin{array}{c}1.0 \pm 1.8 \\
0.55\end{array}$ & $\begin{array}{c}1.0 \pm 1.3 \\
0.60\end{array}$ \\
\hline Thermal comfort & 1 & $\begin{array}{c}0.0 \pm 1.0 \\
0.59\end{array}$ & $\begin{array}{c}0.0 \pm 1.0 \\
0.59\end{array}$ & $\begin{array}{l}0.0 \pm 1.0 \\
0.55\end{array}$ & $\begin{array}{c}1.0 \pm 0.0 \\
\mathbf{0 . 0 0}\end{array}$ \\
\hline Interior lighting & 2 & $\begin{array}{c}1.0 \pm 1.0 \\
0.82\end{array}$ & $\begin{array}{c}1.0 \pm 1.0 \\
0.64\end{array}$ & $\begin{array}{c}1.0 \pm 0.8 \\
0.73\end{array}$ & $\begin{array}{c}2.0 \pm 0.3 \\
0.20\end{array}$ \\
\hline Daylight & 3 & $\begin{array}{l}0.0 \pm 0.0 \\
1.00\end{array}$ & $\begin{array}{c}0.0 \pm 0.0 \\
0.95\end{array}$ & $\begin{array}{c}0.0 \pm 0.8 \\
0.91\end{array}$ & $\begin{array}{c}0.0 \pm 1.3 \\
1.00\end{array}$ \\
\hline Quality views & 1 & $\begin{array}{l}0.0 \pm 0.0 \\
0.77\end{array}$ & $\begin{array}{c}0.0 \pm 1.0 \\
0.55\end{array}$ & $\begin{array}{l}1.0 \pm 1.0 \\
0.45\end{array}$ & $\begin{array}{c}1.0 \pm 0.3 \\
\mathbf{0 . 2 0}\end{array}$ \\
\hline Acoustic performance & 1 & $\begin{array}{c}0.0 \pm 0.0 \\
0.95\end{array}$ & $\begin{array}{c}0.0 \pm 0.0 \\
1.00\end{array}$ & $\begin{array}{c}0.0 \pm 0.0 \\
0.91\end{array}$ & $\begin{array}{c}0.0 \pm 0.0 \\
1.00\end{array}$ \\
\hline
\end{tabular}

Notes: Effect size is considered to be: very high if $|\delta|<0.147$ (bold font), high if $0.147<|\delta|<0.33$ (bold italic font), medium if $0.33<|\delta|<0.474$ (italic font), and low if $|\delta| \geq 0.474$ (normal font).

\subsection{Innovation}

Figure 8 shows the boxplot and Cliff's $\delta$ results in the IN category. According to the boxplot, the median increased from Certified through Silver and Gold to Platinum $(3,5,5$, and 6 achieved points, respectively) with decreases in the range from level to level (1-6,3-6, 4-6, and 6-6 achieved points in Certified, Silver, Gold, and Platinum projects, respectively). According to Cliff's $\delta$, the IN category showed low achievement in Certified, Silver, and Gold projects and very high in Platinum projects. This category includes Innovation credit (five possible points) and LEED accredited professional credit (one possible point) [5]. A LEED-accredited professional was hired in almost all projects (independent of certification level). Thus, the IN credit showed different achievements in Certified, Silver, and Gold and Platinum projects.

\subsection{Regional Priority}

Figure 9 shows the boxplot and Cliff's $\delta$ results in RP category. According to the boxplot, the median increased from Certified through Silver and Gold to Platinum (2, 3, 3, and 4 achieved points, respectively) with decreases in the range of the Certified and Silver projects through Gold to Platinum projects $(1-4,1-4,2-4$, and 3-4 achieved points, respectively). According to Cliff's $\delta$, the RP category showed low achievement in Certified, Silver, and Gold projects and medium in Platinum projects. The RP category includes four possible bonus points, which can be obtained by performing regional-related credits in LT, SS, WE, EA, MR, and EQ categories [5]. However, according to the present results, RP was an unattractive category for Certified, Silver, and Gold projects and received little attention from Platinum projects. 


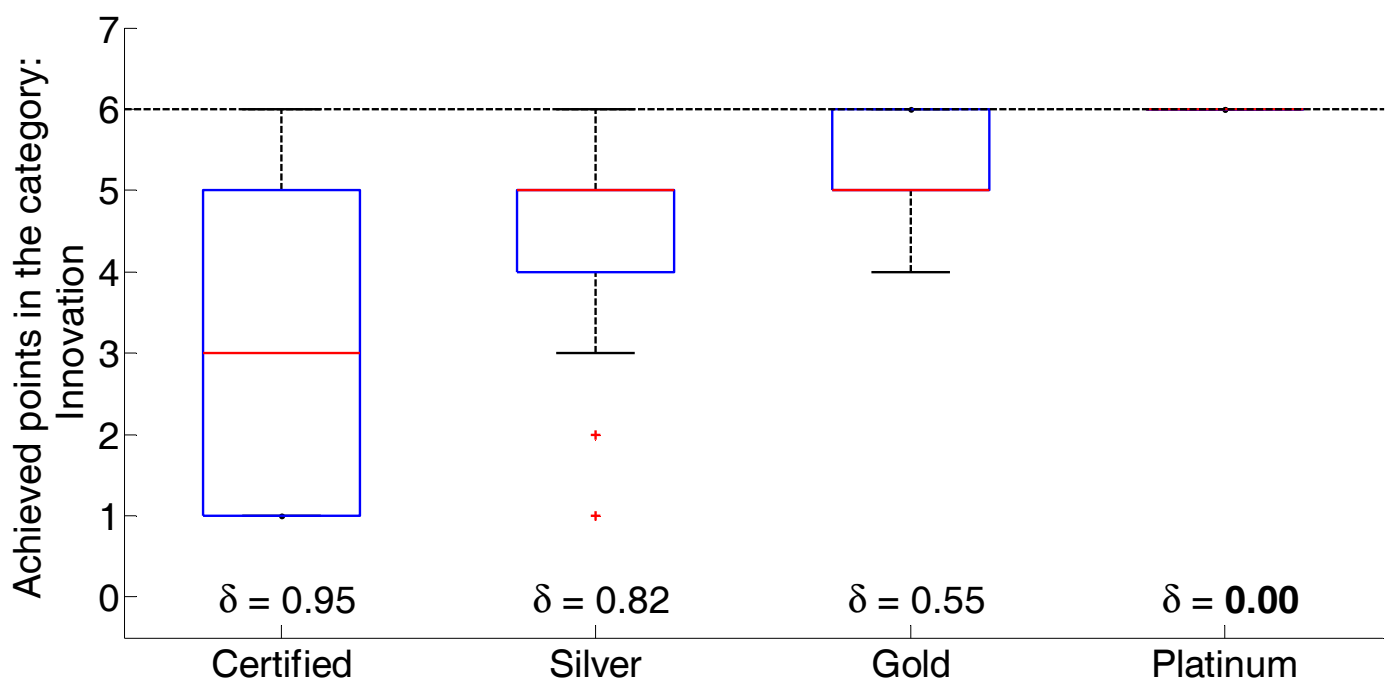

Figure 8. Boxplot results and Cliff's $\delta$ effect size between possible and achieved points in the Innovation (IN) category. Effect size is considered to be: very high if $|\delta|<0.147$ (bold font), high if $0.147<|\delta|<0.33$ (bold italic font), medium if $0.33<|\delta|<0.474$ (italic font), and low if $|\delta| \geq 0.474$ (normal font).

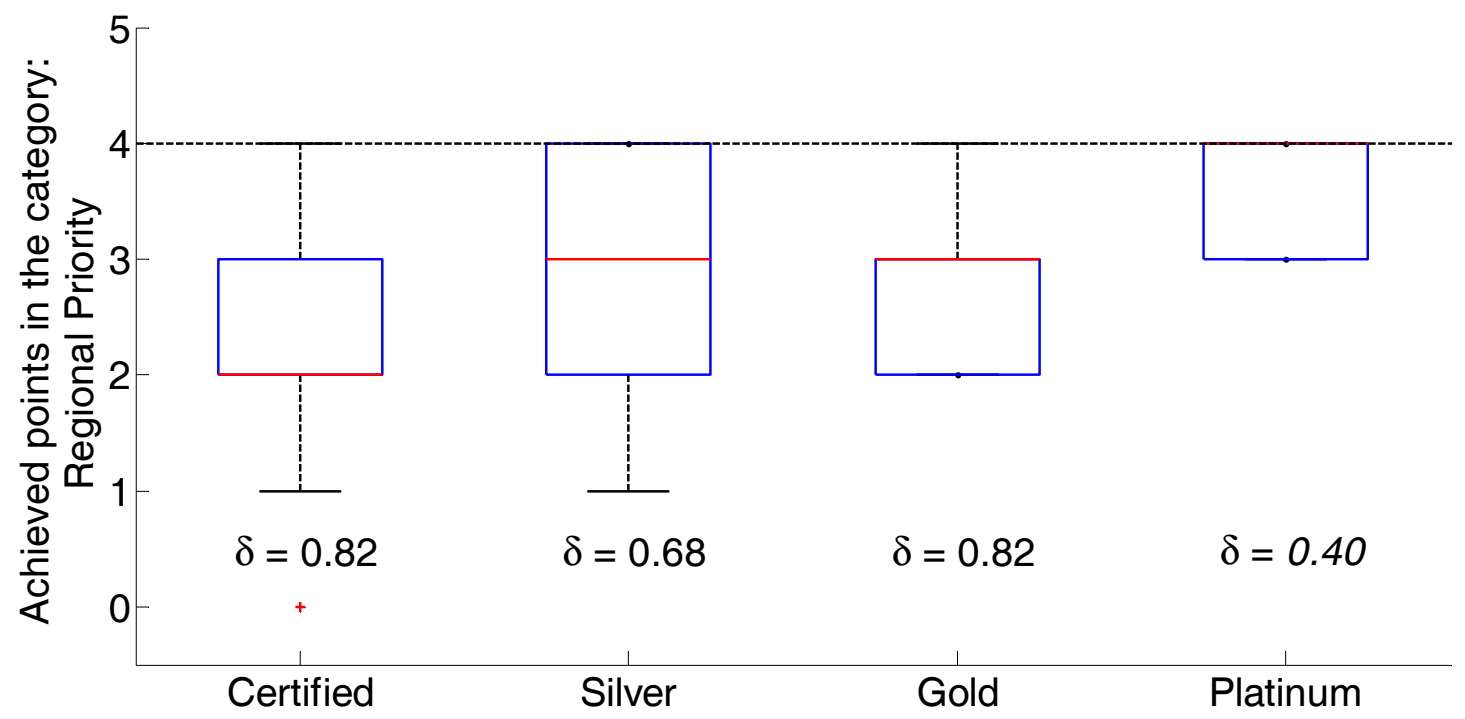

Figure 9. Boxplot results and Cliff's $\delta$ effect size between possible and achieved points in the Regional Priority (RP) category. Effect size is considered to be: very high if $|\delta|<0.147$ (bold font), high if $0.147<|\delta|<0.33$ (bold italic font), medium if $0.33<|\delta|<0.474$ (italic font), and low if $|\delta| \geq 0.474$ (normal font).

\section{Discussion}

The findings of this empirical study of new LEED construction projects certified in 2015-2019 reveal no consistency in achievement points in almost all the categories across the projects for the same certification level. In the LT, WE, MR, and EQ categories, wide ranges of achieved points across the projects were noted for all four levels of certification: Certified, Silver, Gold, and Platinum. This inconsistency in first was discussed by Siew [18], who studied new LEED construction projects from the USGBC database in 2013 and reported large ranges of scores for categories such as SS, WE, $\mathrm{MR}, \mathrm{EQ}$, and IN within the same certification level. This means that different projects teams achieved the same certification level through application of the different credits that were easiest for them to attain. This point-based LEED approach has been criticized for years. In 2006, Scott [29] discussed that the design of truly sustainable architecture is impossible with this LEED point-based approach. 
In 2010, Chang [30] argued that LEED does not devote adequate attention to passive building design principles. In 2014, Shaviv and Pushkar [31] discussed the LEED GOLD Intel Building in Israel, which was designed mainly by improving building energy systems and neglecting passive and low energy building design.

This LEED-NCv4 study also revealed that the SS and EA categories were the best-achieved categories with most credits in these categories being the medium, high, and very high-achieved credits; the WE and EQ categories were the medium-achieved categories with half being medium high-achieved credits; and LT and MR categories were the worst-achieved categories with low-achieved credits. Notably, LEED and other rating systems have been criticized for not considering LCA in their credits [32]. However, as was revealed in this empirical study, although LEED-NCv4 introduced LCA in four of six MR credits, these were poorly achieved in all four certification levels.

Despite that EQ category being recognized here as a medium-achieved category, only low-emitting materials considered as influencing human health are included, omitting the use of other potentially toxic building materials. For example, LEED requires reducing persistent, bioaccumulative, and toxic chemicals only in healthcare-type buildings [5].

Moreover, despite EA being the best-achieved category, only LEED-NCv4 Platinum projects achieved a high level for the Optimize energy performance credit. In this credit, reducing operational energy is prescribed considering building-related and system-related features together. Again, passive and low energy building design can be neglected, achieving the required energy decrease through application of HVAC systems with a high-efficiency performance coefficient [9].

The IN category was found to be only highly achieved in Platinum projects. This empirically confirms that LEED fails to encourage and reward innovation. Cucuzzella [33] analyzed the best-constructed environmental public spaces and buildings from 1970 to 2010 and argued that contemporary society placed more confidence in rating systems prescribe best-known practices and has less desires to develop innovative and sustainable solutions.

Thus, much more research should be invested in developing a weighted green rating system that will encourage project teams to build environmentally friendly sustainable projects and not only seek easy points to achieve certification.

\section{Conclusions}

In this study, Certified, Silver, Gold, and Platinum LEED-NCv4 projects certified from 27 April 2015 to 16 August 2019 in the U.S. were analyzed. The following conclusions were drawn:

(1) The IP and IN categories showed inconsistent low and medium achievement across Certified-Gold projects and consistently high achievement across Platinum projects. The RP category was inconsistently low in Certified-Gold projects and consistently medium in Platinum projects. Thus, these categories need to be improved in further designs to increase their attractiveness for all certification levels.

(2) The SS and EA categories were well designed, in which most of the credits were achieved differently (low/medium/high/very high) in the four certification levels. In the SS category, more credits were achieved in Silver projects compared with Certified projects and in Platinum compared with Gold. In the EA category, more credits were achieved in Gold projects compared to Certified or Silver projects and in Platinum compared to Gold projects. In both the SS and EA categories, the consistency across the projects increased from level to level.

(3) The WE and EQ categories have an average design, in which inconsistency across the projects was identified in the four certification levels and approximately half the credits were achieved differently in the four levels, whereas the other half were achieved in a similar low way in all levels. In the WE category, the differently achieved credits performed better in Platinum projects compared with Certified, Silver, or Gold projects. In the EQ category, the differently achieved credits performed better in higher-level projects such as Silver, Gold, and Platinum compared with 
Certified. However, half of the WE and EQ credits which were poorly achieved in all certification levels need to be improved in their future design.

(4) The LT and MR categories showed the worst design, with inconsistency across the four levels of projects and most of the credits were low-achieved in the four certification levels. These poorly achieved credits also require further improvement.

Funding: This research received no external funding.

Conflicts of Interest: The author declares that there is no conflict of interest.

\section{References}

1. UNEP. United Nations Environment Program for Sustainable Buildings and Construction. 2018. Available online: https://wedocs.unep.org/bitstream/handle/20.500.11822/27140/Global_Status_2018.pdf?sequence= 1\&isAllowed=y (accessed on 12 January 2020).

2. BREEAM. BREEAM Manual 2014. Available online: https://tools.breeam.com/filelibrary/BREEAM\% 20UK\%20NC\%202014\%20Resources/SD5076_DRAFT_BREEAM_UK_New_Construction_2014_Technical_ Manual_ISSUE_0.1.pdf (accessed on 12 January 2020).

3. CASBEE. CASBEE for Buildings (New Construction) Technical Manual. 2014. Available online: http: //www.ibec.or.jp/CASBEE/english/downloadE.htm (accessed on 12 January 2020).

4. Green Star. Technical Manual v3.2. 2017. Available online: https://12253-console.memberconnex.com/ Attachment?Action=Download\&Attachment_id=1347 (accessed on 12 January 2020).

5. LEED. LEED v4 for Building Design and Construction. 2018. Available online: https://www.lorisweb.com/ LEEDv4/GA/GA_READ/GA09_LEED\%20v4\%20BDC_01.5.18_current.pdf (accessed on 12 January 2020).

6. Siew, R.Y.J.; Balatbat, M.C.A.; Carmichael, D.G. A review of building/infrastructure sustainability reporting tools (SRTs). SASBE 2013, 2, 106-139.

7. Głuszak, M. Internationalization, Competiveness and Green Building Certification in Europe. In Europeanization Processes from the Mesoeconomic Perspective: Industries and Policies, 2nd ed.; Stanek, P., Wach, K., Eds.; Cracow University of Economics: Kraków, Poland, 2015; Volume 9, pp. 173-191.

8. Castellano, J.; Ribera, A.; Ciurana, J. Integrated system approach to evaluate social, environmental and economics impacts of buildings for users of housings. Energy Build. 2016, 123, 106-118. [CrossRef]

9. Pushkar, S.; Shaviv, E. Using shearing layer concept to evaluate green rating systems. Archit. Sci. Rev. 2016, 59, 114-125. [CrossRef]

10. Cheng, J.C.P.; Ma, L.J. A non-linear case-based reasoning approach for retrieval of similar cases and selection of target credits in LEED projects. Build. Environ. 2015, 93, 349-361. [CrossRef]

11. LEED. LEED v2.2 for New Construction and Major Renovations. 2005. Available online: https://www. novapolymers.com/wp-content/uploads/2012/05/LEEDforNewConstructions.pdf (accessed on 12 January 2019).

12. Fuerst, F. Building momentum: An analysis of investment trends in LEED and Energy Star-certified properties. J. Retail Leis. Prop. 2009, 8, 285-297. [CrossRef]

13. Wu, P.; Mao, C.; Wang, J.; Song, Y.Z.; Wang, X.Y. A decade review of the credits obtained by LEED v2.2 certified green building projects. Build. Environ. 2016, 102, 167-178. [CrossRef]

14. LEED. LEED v3 for New Construction and Major Renovations. 2009. Available online: https://www.usgbc. org/sites/default/files/LEED\%20v4\%20BDC_07.2.18_current.pdf (accessed on 20 July 2019).

15. Wu, P.; Song, Y.Z.; Shou, W.C.; Chi, H.L.; Chong, H.Y.; Sutrisna, M. A comprehensive analysis of the credits obtained by LEED 2009 certified green buildings. Renew. Sustain. Energy Rev. 2017, 68 Pt 1, 370-379. [CrossRef]

16. Pushkar, S.; Verbitsky, O. LEED-NCv3 Silver and Gold certified projects in the US: An observational study. J. Green Build. 2018, 13, 67-83. [CrossRef]

17. Pushkar, S.; Verbitsky, O. LEED-NC 2009 Silver to Gold certified projects in the US in 2012-2017: An appropriate statistical analysis. J. Green Build. 2019, 14, 83-107. [CrossRef]

18. Siew, R. Evaluating and Enhancing the Impact of Sustainability Reporting Tools (SRTs). Ph.D. Thesis, School of Civil and Environmental Engineering, the University of New South Wales, Sydney, Australia, 2014; 381p.

19. USGBC. US Green Building Council (USGBC). Projects Directory. Available online: https://www.usgbc.org/ projects/new-construction (accessed on 12 January 2020). 
20. MATLAB and Statistics Toolbox Release 2013a; The Math Works, Inc.: Natick, MA, USA, 2013.

21. Cliff, N. Dominance statistics: Ordinal analyses to answer ordinal questions. Psychol. Bull. 1993, 114, 494-509. [CrossRef]

22. Fay, M.P.; Proschan, M.A. Wilcoxon-Mann-Whitney or t-test? On assumptions for hypothesis tests and multiple interpretations of decision rules. Stat. Surv. 2010, 4, 1-39. [CrossRef] [PubMed]

23. Bergmann, R.; Ludbrook, J.; Spooren, W.P.J.M. Different outcomes of the Wilcoxon-Mann-Whitney test from different statistics packages. Am. Stat. 2000, 54, 72-77.

24. Pushkar, S.; Verbitsky, O. Silver and gold LEED commercial interiors: Certified projects. J. Green Build. 2019, 14, 95-113. [CrossRef]

25. Romano, J.; Corragio, J.; Skowronek, J. Appropriate statistics for ordinal level data: Should we really be using t-test and Cohen's d for evaluating group differences on the NSSE and other surveys? In Proceedings of the Annual Meeting of the Florida Association of Institutional Research, Cocoa Beach, FL, USA, 1-3 February 2006; Florida Association for Institutional Research: Cocoa Beach, FL, USA, 2006; pp. 1-33.

26. Cohen, J. A power primer. Psychol. Bull. 1992, 112, 155-159. [CrossRef]

27. Durlak, J.A. How to select, calculate, and interpret effect sizes. J. Pediatr. Psychol. 2009, 34, 917-928. [CrossRef]

28. Volker, M.A. Reporting effect size estimates in school psychology research. Psychol. Sch. 2006, 43, 653-672. [CrossRef]

29. Scott, A. Design Strategies for Green Practice. J. Green Build. 2006, 1, 11-27. [CrossRef]

30. Chang, R. Energy Benchmarking. ASHRAE J. 2010, 52, 74-77.

31. Shaviv, E.; Pushkar, S. Green building standards-Visualization of the building as layers according to lifetime expectancy. Energy Procedia 2014, 57, 1696-1705. [CrossRef]

32. Pushkar, S. Application of Life Cycle Assessment to various building lifetime shearing layers: Site, Structure, Skin, Services, Space, and Stuff. J. Green Build. 2015, 10, 198-214. [CrossRef]

33. Cucuzzella, C. The normative turn in environmental architecture. J. Clean. Prod. 2019, 219, 552-565. [CrossRef]

(C) 2020 by the author. Licensee MDPI, Basel, Switzerland. This article is an open access article distributed under the terms and conditions of the Creative Commons Attribution (CC BY) license (http://creativecommons.org/licenses/by/4.0/). 